A Yeoman's Job in Developing, Refining, Revising, and

Executing a Manualized Group Version of the Clark

and Wells (1995) Model, Although More Remains To Be Done

S.T. Fishman

Pragmatic Case Studies in Psychotherapy, http://pcsp.libraries.rutgers.edu

Volume 2, Module 1, Article 4, pp. 1-8, 02-17-06 [copyright by author]

\title{
Commentary on Identifying and Targeting Idiosyncratic Cognitive Processes in Group Therapy for Social Phobia: The Case of Vumile
}

\section{A Yeoman's Job in Developing, Refining, Revising, and Executing a Manualized Group Version of the Clark and Wells (1995) Model, Although More Remains To Be Done}

\author{
STEVEN T. FISHMAN ${ }^{\text {a,b }}$ \\ ${ }^{a}$ Managing Director and Founder, Institute for Behavior Therapy, New York, NY. \\ $\mathrm{b}$ Correspondence concerning this article should be addressed to Steven T. Fishman, Institute for Behavior Therapy, \\ 104 East 40th St., Suite 206 New York, NY 10016-1801. \\ Email: sfishman@ifbt.com
}

\begin{abstract}
Edwards and Kannan (2006) have done an excellent job in conceiving, conducting, and incorporating findings from follow-up studies to the original Clark and Wells treatment paradigm for social phobia, upon which their therapy group was based. For example, in carrying out their case study, the authors have incorporated many quality control procedures associated with the American Psychological Association's Evidence-Based Practice in Psychology model, such as continuously monitoring each group participant's progress via narratives and normative questionnaires; building in the capability to alter treatment directions when indicated and to individualize the cognitive approach for each participant; and designing relapse prevention mechanisms into the treatment. On the other hand, as I view the study, there are limitations and issues about how it was conducted and interpreted. These questions include whether the most validated assessment measures were employed; whether in fact social skills training took place but was not conceptualized as such; and whether there is an alternative explanation of the outcome results with the client Vumile that was not explored. Still overall, Edwards and Kannan's study of Vumile and the other members in their group makes a very valuable contribution in carefully and systematically documenting how individuals presenting with topographically equivalent problems can progress for varied reasons that can be measured and treated differently within a manualized therapy. This Commentary ends with my reflections about different knowledge benefits the PCSP journal can offer, particularly for the clinical practitioner.
\end{abstract}

Key words: Cognitive-behavioral treatment; social phobia; evidence-based practice; group therapy 
A Yeoman's Job in Developing, Refining, Revising, and

Executing a Manualized Group Version of the Clark

and Wells (1995) Model, Although More Remains To Be Done

S.T. Fishman

Pragmatic Case Studies in Psychotherapy, http://pcsp.libraries.rutgers.edu

Volume 2, Module 1, Article 4, pp. 1-8, 02-17-06 [copyright by author]

It's in the air -- with the American Psychological Association's (APA) Task Force on Empirically Based Practice in Psychology (EBPP) (Goodheart, 2005) recommending that clinicians utilize "best research available" in their clinical practice of psychology, with HIPPA requiring stringent HIPPA rules for confidentiality, and with third-party payers "encouraging" the use of empirically supported treatments (ESTs) in practice -- public policy is demanding greater accountability and cost containment measures (Goodheart (2005) in the clinical practice of psychology than ever before. With these new implicit and explicit demands for "best research available" in clinical practice, the birth of the PSCP online journal is timely. PCSP will provide a platform for case studies and clinical research that with time will become an invaluable resource (a) for practitioners seeking the "best available research" for treating the problems encountered in their respective practices, and (b) for clinical researchers who are seeking to replicate, refine, and expand the existing studies to insure more viable treatment for the whole spectrum of emotional and behavioral problems. (See the "About This Journal" section at the end of this Commentary on the clinical utility of $P C S P$ ).

Edwards and Kannan's (2006, this module) Case of Vumile is representative of the type of clinical research that will be a welcome addition to the PSCP data-base archives because it contains all the elements proposed by the APA's EBPP Task Force (Goodheart 2005), and because it conforms to the editorial policy of $P S C P$. This very ambitious and comprehensive treatment program for social phobia is intended to validate, refine, and expand an existing individual assessment model of Clark and Wells (1995) and the manualized treatment model developed by Clark (1997).

\section{SOCIAL PHOBIA}

Before commenting on the present study, I want to underscore the importance of developing a viable treatment program for this most menacing of problems, social phobia. Why menacing? Even though it is reported in epidemiological studies ( Korbly \& Simon, 2003) that social phobias occur in about $13 \%-15 \%$ of the population, I have found in my own practice -and I'm sure other practitioners would concur -- that it is the most frequently presented problem in one form or another (e.g., performance fears, assertive difficulties, low self-esteem, dating difficulties, or authority figure problems), and secondary to many of the other problems (such as obsessive-compulsive disorder, generalized anxiety disorder, or panic disorder) with which we are presented. Consequently, we can assume that the occurrence of social phobias are grossly underreported. Needless to say, social anxieties and phobias are severely debilitating, because they cross-cut every dimension of an individual's functioning (such as work, relationships, sex life, and recreation), for just about every human endeavor involves other people or some form of performance.

As Edwards and Kannan point out, the treatment of social phobias has since the very beginning of cognitive-behavioral therapy in the mid-1950's been a target problem for practitioners using a combination of a skill-based approaches (e.g., social skills training), anxiety 
A Yeoman's Job in Developing, Refining, Revising, and

Executing a Manualized Group Version of the Clark

and Wells (1995) Model, Although More Remains To Be Done

S.T. Fishman

Pragmatic Case Studies in Psychotherapy, http://pcsp.libraries.rutgers.edu

Volume 2, Module 1, Article 4, pp. 1-8, 02-17-06 [copyright by author]

reduction techniques (e.g., desensitization and various relaxation methods), and various cognitive restructuring methods. According to these researchers, with further refinements of our understanding of the problem and the techniques themselves, newer, more streamlined information processing models for the treatment of social phobias have evolved. The Case of Vumile is based on such a model (Clark \& Wells, 1995; Clark, 1997).

\section{THE OVERALL PROGRAM}

Edwards and his students have done an excellent job in conceiving, conducting, and incorporating findings from follow-up studies to the original Clark and Wells model; and they have expanded the original model to include a group format with its attendant benefits -- such as psychoeducation, a platform for the practice of new behaviors with constructive feedback, and a supportive and sharing environment -- for more efficient treatment delivery. The Case of Vumile is one of a series of individual case studies that were products of their overall group treatment program. Additionally, there were many other refinements employed by Edwards and his group that conform to the new EBPP standards for clinical research (Goodheart, 2005) built into the conceptual framework of the program. These include but are not limited to: (a) full disclosure to participants as to what the program entails; (b) managing the program with utmost concern for confidentiality; (c) continual monitoring of the participant's progress via narratives and objective instruments; (d) capability within the program to alter treatment directions when indicated; (e)mechanisms built into the program for individualizing the cognitive approach for each participant; (f) relapse prevention mechanisms incorporated into the program; and (g) adequate follow-up to insure maintenance of gains. The innovative thinking, refinements, and mechanisms for sound clinical research that these authors evince, in my opinion, are exemplary.

\section{ISSUES AND PROBLEMS}

The measures and analysis. But, in spite of the monumental effort put forth by Edwards and Kannan on their group program, it is not without its problems. They utilized a repeated measure design for each individual in the group, but the quantitative instruments they employed were basically those used in the original series of studies by Clark and Wells (1995). Despite their face validity, these instruments are essentially unvalidated measures -- with the exception of both the Beck Depression Inventory (BDI -- Beck, Steer, \& Brown, 1993) and the Beck Anxiety Inventory (BAI -- Beck \& Steer, 1996), and even the BDI's validity had been recently called into question. (As an aside, it is hard to believe that Vumile, the subject of the present study, entered the program with a very low depression score BDI despite feeling "miserable" with little hope for change. This raises some question about the validity of the measure in certain situations.)

Most of the analysis in this study was qualitative, specifically based on observations as documented in narratives that were done by the consensus of the senior author and two of his students. Obviously in clinical research, one can rely more on a qualitative analysis, but with a formal treatment program as the present one, it would have lent greater credibility to outcomes if 
A Yeoman's Job in Developing, Refining, Revising, and

Executing a Manualized Group Version of the Clark

and Wells (1995) Model, Although More Remains To Be Done

S.T. Fishman

Pragmatic Case Studies in Psychotherapy, http://pcsp.libraries.rutgers.edu

Volume 2, Module 1, Article 4, pp. 1-8, 02-17-06 [copyright by author]

these researchers had used some validated instruments specific to social anxiety. There are now many of these (e.g., Heimberg and Becker, 2002). In addition, I would suggest that it would have been more persuasive with three observers, particularly in light of the fact that there were hierarchal differences among the observers.

Outcomes. Another problem is that there is little attempt on the part of these researchers to define discrete outcomes of treatment with each group participant. It is therefore hard to define clinically successful outcomes. For example, is it a reported reduction of anxiety, a change on a paper-and-pencil inventory, or the actual initiation of behaviors in those situations that were being avoided?

Safety behaviors. The basic theory driving the Clark and Wells model simply stated is that a socially phobic individual fears the way they are being perceived by others. The fears of being perceived as "inadequate" in some manner gives rise in these individuals to a cascading of dysfunctional thoughts and images, from the anticipation of a social event to the situation itself to the post-mortem catastophizing about their performance. It is primarily these dysfunctional thoughts that cause feelings of self-consciousness and consequent anxiety. This anxiety eventuates in clients mobilizing a host of "safety behaviors" or mechanisms (e.g., avoiding eye contact, wearing lose fitting clothes to avoid perspiration, or speaking rapidly to make sure they remember what they want to say) to help to avoid the occurrence of negative evaluation these individuals so fear in the social event. According to these researchers, it is these "safety behaviors" that actually cause the very outcomes that the socially phobic fears; for they ultimately interfere with the spontaneity and naturalness that these researchers deem necessary for sound social interaction. The focus of treatment is the parsing out and modifying of the dysfunctional thoughts and the elimination of the self-protective "safety behaviors." In both a videotape session with each participant in the study, as well as in a series of behavioral real-time experiments, participants are exhorted to "drop" the safety behaviors because of their selfdefeating nature.

It seems to me, however, that what these researchers call "safety behaviors" are, in actuality, habitual maladaptive behaviors that require considerably more than the exhortation to "drop" them. From my own clinical experience, the mere exhortation of a patient to "drop" a behavior or "change" a dysfunctional thought is frequently met with resistance or bewilderment on the part of a patient. Longstanding habitual, albeit maladaptive, behavior requires a protracted effort on the part of the patient. The first step in the change process is awareness, and step two is engaging in a new, incompatible responses to prevent the onset of the habitual behavior. Clark and Wells (1995) have implied that conventional treatment (e.g. social skills training and relaxation training) within the social context are contraindicated because they impede social interaction; and, in fact, may unwittingly become detrimental safety behaviors. To my way of thinking, in the present study, these "safety behaviors" were not being "dropped." Rather, I view these behaviors as being modified by feedback during role plays in group treatment sessions and/or by Vumile's own reports of self-talk during his real-time behavioral experiments. This 
A Yeoman's Job in Developing, Refining, Revising, and

Executing a Manualized Group Version of the Clark

and Wells (1995) Model, Although More Remains To Be Done

S.T. Fishman

Pragmatic Case Studies in Psychotherapy, http://pcsp.libraries.rutgers.edu

Volume 2, Module 1, Article 4, pp. 1-8, 02-17-06 [copyright by author]

self-talk and the conscious awareness of his dysfunctional beliefs had to "interfere with his spontaneity," hence cannot be considered different from conventional social skills training. Further, Vumile also reported that he reminded himself through "self-talk" not to engage in selfdefeating thoughts during social interactions as well. Moreover, in spite of Edwards and Kannan being emphatic about not doing social skills training, I would maintain that components of the program -- the role-playing with feedback, the before-and-after videotape review with feedback, and a coaching session like the one received by Vumile between the seventh and eighth session if not social skills training, are certainly a very close cousin to such training. Isn't it just a matter of semantics?

Rapee \&Heimberg (1997), who developed a cognitive model and a group program (Heimberg \& Becker, 2002) that parallels the Clark and Wells model, use exposure-based techniques and emphasize the modification of dysfunctional beliefs in role-plays, but also instruct their group participants to take a more active approach in modifying their automatic thoughts in the social interaction in order to reduce their anxiety. They use social skills training and coaching only when indicated. They believe, as do Clark and Wells, that most people -phobic or not -- have the necessary skills for effective social interaction, but are being impeded by dysfunctional thoughts and images. Yet Heimberg and Becker's (2002) approach is a more active intervention program than a passive one.

Another explanation. Edwards and Kannen's central thesis in the Vumile case is that Vumile failed to make significant progress until after the completion of the program, when he had an epiphany that "all women were looking at him in a ridiculing or pitying way." This belief (and related images) created intense anxiety that resulted in his inability to make eye contact in social discourse with women. Edwards and Kannan concluded from this that idiosyncratic beliefs and images have to be parsed out and restructured before, in many cases, real progress can be made in treatment. Modification of the behavior alone is insufficient for lasting change. As others have indicated (Persons \& Tompkins, 1997; Tompkins, 1997), the only effective treatment, particularly in exposure-based treatment, is one that modifies the clients' underlying belief about themselves or about the presenting maladaptive behavior -- then and only then can lasting change occur.

I would like to advance the possibility of another, more parsimonious, explanation for Vumile's late progress. Perhaps, simply, there was a consolidation of gains after spending months of involvement in the program participating in group discussions and numerous behavioral experiments, to which he seemed to be most dedicated and committed.

Generalization. Finally, I feel compelled to resurrect the age-old argument about the generalizability of results from efficacy research to the clinical setting because, from my experience, social phobias rarely occur without co-morbidity (Kolby \& Simon, 2002). When Edwards and Kannan rule out individuals for their study who are on psychotropic medication or have other psychiatric conditions, then the generalizability into the clinical setting with a 
A Yeoman's Job in Developing, Refining, Revising, and

Executing a Manualized Group Version of the Clark

and Wells (1995) Model, Although More Remains To Be Done

S.T. Fishman

Pragmatic Case Studies in Psychotherapy, http://pcsp.libraries.rutgers.edu

Volume 2, Module 1, Article 4, pp. 1-8, 02-17-06 [copyright by author]

representative clinical population is questionable. In a recent survey article of internship facilities in the U.S. (Woody, Weisz, \& McLean, 2005), it was found that, contrary to expectation, over the past 10 years there has been a decline in teaching of ESTs to interns. Of particular relevance to the generalizability issue was a point advanced by these authors to explain this unforeseen finding. Specifically, they suggest that ESTs are basically products of efficacy research in which only one variable at a time is typically manipulated; and hence, ESTs really don't apply to the more complex problems and permutations of populations that are encountered in "real" clinical practice. Such a position is rather extreme and is tantamount to "throwing the baby out with the bathwater." This problem can be remedied by future clinical research that refines and expands existing studies in various problem areas to include patients with co-morbid problems or other variations of populations, as advocated by this journal.

\section{CONCLUSION}

When Edwards and Kannan examined the overall results of their program, the results appeared at first blush to be spurious, since there was tremendous variability in outcomes among the seven participants. They concluded, and rightly so, that individuals change for different reasons, at different rates, and their changes are reflected in different ways: through the paperand-pencil inventories, through qualitative reports of feeling better in social contexts, or even better, through actually observed changes in their behavioral functioning. In addition those participants who did make progress in the treatment program responded to different aspects of the program. Simply stated, it can be deduced from these findings that individuals presenting topographically equivalent problems can progress for different reasons that have to be measured and treated differently.

Accordingly, Edwards and Kannan have recommended further refinements to their manualized group program. The overall approach provides a framework wherein treatment is:

a) highly individualized, allowing sufficient space in the program for culling out idiosyncratic beliefs and even images,

b) inclusive of a variety of measures (hopefully validated instruments),

c) representative of a broad spectrum of treatment approaches that are included, and

d) overall, fluid enough to permit the shifting of treatment focus to meet the everchanging needs of the individual as the treatment unfolds.

Despite some of the problems mentioned above, Edwards and Kannan have done a yeoman's job in developing, refining, revising, and executing the manualized version of the Clark and Wells (1995) model. They too recognize that there is work is left to be done to make it a viable model and treatment program for social anxiety. As would be hoped in case study research (Edwards, Dattilio, \& Bromley, 2004), the Case of Vumile lends further credence to the Clark and Wells conceptual model and to Clark's treatment manual. With their findings from the 
A Yeoman's Job in Developing, Refining, Revising, and

Executing a Manualized Group Version of the Clark

and Wells (1995) Model, Although More Remains To Be Done

S.T. Fishman

Pragmatic Case Studies in Psychotherapy, http://pcsp.libraries.rutgers.edu

Volume 2, Module 1, Article 4, pp. 1-8, 02-17-06 [copyright by author]

present case study, Edwards and Kannan have set the stage for future clinical research with the Clark and Wells model. I commend their efforts in the present study.

\section{ABOUT THIS JOURNAL}

As a long time practitioner (35 years in the practice of cognitive-behavior therapy), I enthusiastically endorse $P S C P$, not only for its intended, putative purpose to provide the "best available" research, but for other reasons -- namely, because of its online nature, more space is available for each article and for associated Commentaries than a conventional journal allows, so authors (practitioners, researchers, theorists, and methodologists) can state their cases and Commentaries more comprehensively. This affords readers greater insights into the thinking of other clinicians, who are in a sense able to "think out loud" in their conceptualization, formulation, and description of treatment course for the cases presented. The authors' "thinking out loud" can be an excellent learning tool for new language and alternative perspectives (and even alternate theoretical orientations) on a problem, which can then be incorporated into the readers' own clinical practices. The opportunity for extended appendices, as illustrated in the Edwards and Kannen case study, also provides space for including specific materials and instruments that were used in the case and that both clinicians and researchers can then employ in their own research and practices. PSCP provides a fount of information for the most up-todate practice (as ever evolving) for various theoretical approaches, populations, clinical issues, and problem areas. Regular readers will have their clinical functioning shaped into more responsible practice, ultimately assuring the best treatment for the consumers of psychotherapy, our patients.

\section{REFERENCES}

Beck, A. T. \& Steer, R.A. (1993). Beck Anxiety Inventory Manual. San Antonio TX: Psychological Corporation.

Beck, A. T., Steer, R.A., \& Brown, G.K. (1996). Beck Depression Inventory-II Manual. San Antonio TX: Psychological Corporation.

Clark, D. M. (1997). Cognitive therapy for social phobia: Some notes for therapists. Oxford: University of Oxford, Department of Psychiatry.

Clark, D. M. \& Wells, A.(1995). A cognitive model of social phobia. In R. M. Heimberg, M. Leibowitz, D. Hope, \& F. Schneier (Eds.), Social phobia: Diagnosis, assessment and treatment (pp. 69-93). New York: Guilford.

Edwards, D.J.A., Dattilio, F.M., \& Bromley, D.B. (2004). Developing evidence-based practice: The role of case-based research. Professional Psychology: Research and Practice, 35, 589-597.

Edwards, D.J.A., \& Kannan, S. (2006). Identifying and targeting idiosyncratic cognitive processes in group therapy for social phobia: The case of Vumile. Pragmatic Case Studies in Psychotherapy [Online], Vol. 2(1), Article 1. Available: http://hdl.rutgers.edu/1782.1/pcsp_journal 
A Yeoman's Job in Developing, Refining, Revising, and

Executing a Manualized Group Version of the Clark

and Wells (1995) Model, Although More Remains To Be Done

S.T. Fishman

Pragmatic Case Studies in Psychotherapy, http://pcsp.libraries.rutgers.edu

Volume 2, Module 1, Article 4, pp. 1-8, 02-17-06 [copyright by author]

Goodheart, C.D. (2005). Placing psychotherapy case studies within the framework of the APA evidence-based practice in psychology (EBPP) model. Pragmatic Case Studies in Psychotherapy [Online], Vol. 1(3), Article 2. Available: http://hdl.rutgers.edu/1782.1/pcsp_journal

Hackmann, A., Clark, D.M., \& McManus, F. (2000). Recurrent images and early memories of social phobia. Behaviour Research and Therapy, 38, 601-610.

Heimberg, R.G., \& Becker, R.E (2002). Cognitive-behavioral group therapy for social phobia: Basic mechanisms and clinical strategies. New York: Guilford.

Korbly, N.B. \& Simon, N.M (2003). Social anxiety disorder: Phenomenology, epidemiology and comorbidity. In Pollack, M.P., Simon, N.M., \& Otto, M.W. (Eds.). Social anxiety disorder: Research and practice. New York: Professional Publishing Group.

Krochmalik, A., Jones, M.K., \& Menzies, R.G. ( 2001). Danger ideation reduction therapy (DIRT) for treatment-resistant compulsive washing. Behavior Research and Therapy, 39, 897-912.

Lange, A. J., \& Jakubowski, P. (1976). Responsible assertive behavior. Champaign, IL: Research Press.

McManus, F., Clark, D.M., \& Hackmann, A. (2000). Specificity of cognitive biases in social phobia. Behavioral and Cognitive Psychotherapy, 28, 201-209.

Persons, J. B., \& Tompkins, M. A. (1997). Cognitive-behavioral case formulation. In T.D.Eells (Ed.), Handbook of psychotherapy case formulation, pp. 314-339. New York: Guilford.

Rapee, R.M., \& Heimberg, R.G. (1997). A cognitive-behavioral model of anxiety in social phobia. Behaviour Research and Therapy, 35, 741-756..

Tompkins, M. A. (1997). Case formulation. In R.L. Leahy (Ed.), Practicing cognitive therapy: A guide to interventions (pp. 37-59). Northvale, NJ: Jason Aronson.

Woody, S.R., Weisz, J., \& McLean, C. (2005). Empirically supported treatments: 10 Years Later. The Clinical Psychologist, 58 (4), 5-11. 